\title{
openheart Cardiac reserve by 6-minute walk stress echocardiography in systemic sclerosis
}

\author{
Miharu Arase, ${ }^{1,2}$ Kenya Kusunose (D) , 2 Sae Morita, ${ }^{3}$ Natsumi Yamaguchi, ${ }^{3}$ \\ Yukina Hirata, ${ }^{3}$ Susumu Nishio, ${ }^{3}$ Yuichiro Okushi, ${ }^{2}$ Takayuki Ise, ${ }^{2}$ Takeshi Tobiume, ${ }^{2}$ \\ Koji Yamaguchi, ${ }^{2}$ Daiju Fukuda, ${ }^{4}$ Shusuke Yagi, ${ }^{2}$ Hirotsugu Yamada (D) , \\ Takeshi Soeki, ${ }^{2}$ Tetsuzo Wakatsuki, ${ }^{2}$ Masataka Sata ${ }^{2}$
}

\begin{abstract}
- Additional material is published online only. To view, please visit the journal online (http://dx.doi.org/10.1136/ openhrt-2020-001559).
\end{abstract}

To cite: Arase M, Kusunose K, Morita S, et al. Cardiac reserve by 6 -minute walk stress echocardiography in systemic sclerosis. Open Heart 2021;8:e001559. doi:10.1136/ openhrt-2020-001559

Received 22 December 2020 Revised 23 January 2021 Accepted 8 February 2021

\section{Check for updates}

(c) Author(s) (or their employer(s)) 2021. Re-use permitted under CC BY. Published by BMJ.

${ }^{1}$ Department of Emergency and Critical Care Medicine, Tokushima University Hospital, Tokushima, Japan

${ }^{2}$ Department of Cardiovascular Medicine, Tokushima University Hospital, Tokushima, Japan ${ }^{3} U$ Iltrasound Examination Center, Tokushima University Hospital, Tokushima, Japan

${ }^{4}$ Department of Cardio-Diabetes Medicine, Tokushima University Graduate School of Medicine, Tokushima, Japan ${ }^{5}$ Department of Community Medicine for Cardiology, Tokushima University Graduate School of Medicine, Tokushima, Japan

Correspondence to Dr Kenya Kusunose; kusunosek@tokushima-u.ac.jp

\section{ABSTRACT}

Objectives There is a high prevalence of left ventricular diastolic dysfunction (LVDD) in systemic sclerosis (SSc) which is associated with high mortality. Thus, early detection of LVDD could be important in management of SSc. We hypothesised that exercise echocardiography in SSc patients with normal resting haemodynamics may expose early phase LVDD, which could affect its prognosis, defined as cardiovascular death and unplanned hospitalisation for heart failure.

Methods Between January 2014 and December 2018, we prospectively enrolled 140 patients with SSc who underwent 6-minute walk (6MW) stress echocardiographic studies with normal range of estimated mean pulmonary arterial pressure (mPAP) $(<25 \mathrm{~mm} \mathrm{Hg})$ and mean pulmonary artery wedge pressure (mPAWP) $(<15 \mathrm{~mm} \mathrm{Hg})$ at rest. We used $\triangle \mathrm{mPAP} / \triangle$ cardiac output (CO) to assess pulmonary vascular reserve and $\triangle \mathrm{mPAWP} / \triangle \mathrm{CO}$ to assess $\mathrm{LV}$ cardiac reserve between resting and post-6MW.

Results During a median period of 3.6 years (IQR 2.0-5.1 years), 25 patients $(18 \%)$ reached the composite outcome. Both $\triangle \mathrm{mPAP} / \triangle \mathrm{CO}$ and $\triangle \mathrm{mPAWP} / \triangle \mathrm{CO}$ in patients with events were significantly greater than in those without events $(8.9 \pm 3.8 \mathrm{~mm} \mathrm{Hg} / \mathrm{L} / \mathrm{min}$ vs $3.0 \pm 1.7 \mathrm{~mm} \mathrm{Hg} / \mathrm{L} / \mathrm{min}$; $\mathrm{p}=0.002$, and $2.2 \pm 0.9 \mathrm{~mm} \mathrm{Hg} / \mathrm{L} / \mathrm{min}$ vs $0.9 \pm 0.5 \mathrm{~mm} \mathrm{Hg} / \mathrm{L} /$ min; $p<0.001$, respectively). Patients with both impaired $\mathrm{LV}$ cardiac reserve ( $\triangle \mathrm{mPAWP} / \Delta \mathrm{CO}>1.4 \mathrm{~mm} \mathrm{Hg} / \mathrm{L} / \mathrm{min})$ and impaired pulmonary vascular reserve $(\triangle \mathrm{mPAP} / \triangle \mathrm{CO}>3.0$ $\mathrm{mm} \mathrm{Hg} / \mathrm{L} / \mathrm{min}$ ) had worse outcomes compared with those without these abnormalities $(p<0.001)$.

Conclusion The 6MW stress echocardiography revealed impaired LV cardiac reserve in SSc patients with normal resting haemodynamics. Furthermore, LV cardiac reserve independently associates with clinical worsening in SSc, providing incremental prognostic utility, in addition to pulmonary vascular parameters.

\section{INTRODUCTION}

Systemic sclerosis ( $\mathrm{SSc}$ ) is an autoimmune connective tissue disease characterised by fibrosis of the skin and internal organs, and vasculopathy. ${ }^{1}$ It is well known that SSc complications are secondary to pulmonary arterial hypertension $(\mathrm{PAH})$, interstitial lung disease and renal disease. ${ }^{2}{ }^{3}$ Moreover, primary cardiac involvement in

\section{Key questions}

What is already known on this subject?

- The myocardial involvement of systemic sclerosis (SSc) clinically causes cardiac dysfunction, especially left ventricular diastolic dysfunction (LVDD). Several studies have shown that LVDD in SSc is highly prevalent and is associated with increased risk of clinical worsening. In addition, LVDD may occur before clinical manifestation.

What does this study add?

- $\triangle \mathrm{mPAP} / \triangle \mathrm{CO}$ and $\triangle \mathrm{mPAWP} / \triangle \mathrm{CO}$ in the event group were significantly increased compared with the non-event group.

- Impaired LV cardiac reserve and pulmonary vascular reserve were independent predictors of clinical worsening in SSc.

How might this impact on clinical practice?

- Exercise echocardiography may reveal an early stage of LVDD, despite showing normal resting filling pressure.

- These results indicate that 6-minute stress echocardiographic study may predict a high-risk group of patients with SSc.

SSc, such as myocardial damage, fibrosis of the conduction system, pericardial and valvular disease, is a common complication of SSc. ${ }^{2}$ The general pathogenetic process at the myocardial level leads to focal recurrent ischaemia and immunoinflammatory damage, resulting in myocardial fibrosis. ${ }^{4}$ This myocardial involvement clinically causes cardiac dysfunction, especially left ventricular diastolic dysfunction (LVDD). Several studies have shown that LVDD in SSc is highly prevalent $(23 \%-62 \%)$ and is associated with increased risk of mortality. ${ }^{5-7}$ In addition, LVDD may occur before clinical manifestation. Thus, early detection of LVDD in patients with SSc is clinically important.

Recently, it has been demonstrated that exercise echocardiography may evaluate an 


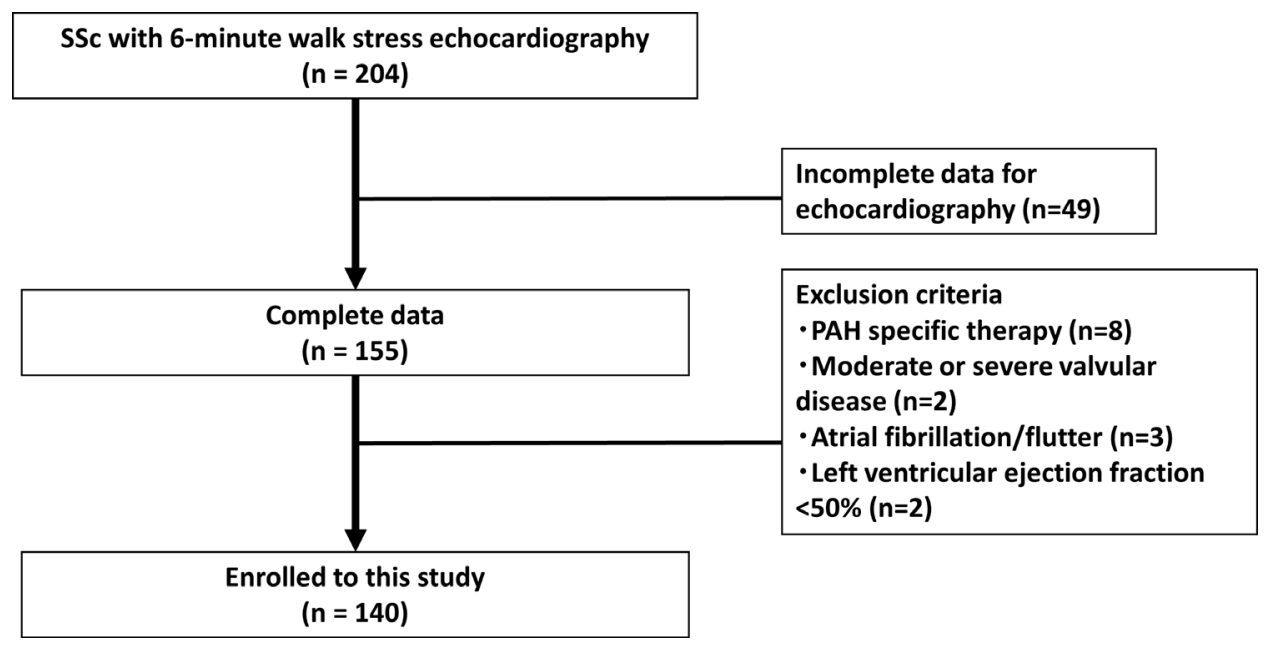

Figure 1 Patient selection. PAH, pulmonary arterial hypertension; SSc, systemic sclerosis.

\begin{tabular}{|c|c|c|c|c|}
\hline & All & Event (+) & Event (-) & $P$ value \\
\hline Number & 140 & 25 & 115 & - \\
\hline Age & $61 \pm 12$ & $62 \pm 10$ & $60 \pm 12$ & 0.54 \\
\hline Male, \% & $14(10)$ & $1(4)$ & $13(11)$ & 0.11 \\
\hline Body mass index & $22 \pm 3$ & $22 \pm 3$ & $22 \pm 3$ & 0.88 \\
\hline WHO Class I/II/III/IV & $27 / 82 / 31 / 0$ & $5 / 16 / 4 / 0$ & $22 / 66 / 27 / 0$ & 0.54 \\
\hline \multicolumn{5}{|l|}{ History } \\
\hline $\begin{array}{l}\text { Disease duration, } \\
\text { months }\end{array}$ & 1.7 & 1.5 & 1.7 & 0.75 \\
\hline \multicolumn{5}{|l|}{ Medication } \\
\hline $\begin{array}{l}\text { Antihypertensive drugs, } \\
\%\end{array}$ & $2(1)$ & $0(0)$ & $2(2)$ & 0.16 \\
\hline Diuretic, \% & $3(2)$ & $1(4)$ & $2(2)$ & 0.59 \\
\hline Anticoagulants, \% & $0(0)$ & $0(0)$ & $0(0)$ & - \\
\hline \multicolumn{5}{|l|}{ Respiratory function } \\
\hline$\% \mathrm{EFV}_{1}, \%$ & $80 \pm 4$ & $82 \pm 6$ & $79 \pm 4$ & 0.82 \\
\hline$\% F V C, \%$ & $109 \pm 13$ & $113 \pm 15$ & $107 \pm 12$ & 0.34 \\
\hline$\%$ DLCO & $80 \pm 13$ & $81 \pm 14$ & $79 \pm 11$ & 0.53 \\
\hline \multicolumn{5}{|l|}{$\begin{array}{l}\text { Baseline } \\
\text { haemodynamics }\end{array}$} \\
\hline $\mathrm{HR}$, bpm & $68 \pm 12$ & $68 \pm 10$ & $67 \pm 12$ & 0.67 \\
\hline Systolic BP, mm Hg & $123 \pm 20$ & $122 \pm 22$ & $123 \pm 19$ & 0.93 \\
\hline Diastolic BP, mm Hg & $68 \pm 10$ & $68 \pm 10$ & $69 \pm 10$ & 0.68 \\
\hline $\mathrm{SpO}_{2}, \%$ & $98 \pm 1$ & $97 \pm 2$ & $98 \pm 1$ & 0.53 \\
\hline \multicolumn{5}{|c|}{ Post-6-minute walk haemodynamics } \\
\hline $\mathrm{HR}, \mathrm{bpm}$ & $90 \pm 17$ & $92 \pm 18$ & $89 \pm 16$ & 0.54 \\
\hline Systolic BP, mm Hg & $128 \pm 25$ & $129 \pm 22$ & $128 \pm 25$ & 0.79 \\
\hline Diastolic BP, mm Hg & $66 \pm 15$ & $70 \pm 19$ & $65 \pm 14$ & 0.22 \\
\hline $\mathrm{SpO}_{2}, \%$ & $96 \pm 3$ & $96 \pm 2$ & $96 \pm 3$ & 0.80 \\
\hline 6MW distance, $\mathrm{m}$ & $432 \pm 89$ & $451 \pm 94$ & $428 \pm 87$ & 0.26 \\
\hline
\end{tabular}

Data are presented as number of patients (percentage) and mean \pm SD. $\mathrm{BP}$, blood pressure; \%DLCO, diffusing capacity for carbon monoxide; $\% \mathrm{FEV} 1$, percent forced expiratory volume in $1 \mathrm{~s}$; \%FVC, percent forced vital capacity; HR, heart rate; MCTD, mixed connective tissue disease; $\mathrm{SpO}_{2}$, percutaneous oxygen saturation; SSc, systemic sclerosis. early stage of LVDD, despite showing normal resting filling pressure. ${ }^{8}$ Several stress methods are extensively used in the clinical setting, and among them, a 6-minute walk (6MW) test is a simple, easy, inexpensive and widely used method. In fact, our previous studies showed that measuring $\Delta$ mean pulmonary artery pressure $(\mathrm{mPAP}) / \Delta$ cardiac output $(\mathrm{CO})$ by $6 \mathrm{MW}$ stress echocardiography can be associated with development of pulmonary hypertension (PH); thus, it is effective in assessing right-sided haemodynamic responses in SSc. ${ }^{9}$ In contrast, the balance of mean pulmonary arterial wedge pressure (mPAWP) and cardiac output $(\mathrm{CO})$ is essential for the assessment of early LVDD. ${ }^{10}$ From the viewpoint of the Frank-Starling mechanism, $\mathrm{CO}$ increases as LV filling pressure (eg, PAWP) elevates in normal subjects. However, patients with severely impaired diastolic dysfunction are unable to augment their cardiac output effectively even though LV filling pressure is significantly elevated. We hypothesised that SSc patients with normal resting haemodynamics may present an early phase of LVDD measured by mPAWP and $\mathrm{CO}$ with exercise echocardiography, and lead to a model to predict long-term outcomes. We sought to (1) evaluate early phase LVDD with a 6MW stress echocardiographic study in our SSc group; and (2) assess the prognosis in those patients using variables of $6 \mathrm{MW}$ stress echocardiography.

\section{METHODS}

\section{Data sharing statement}

Individual anonymised data supporting the analyses contained in the manuscript will be made available on reasonable written request from researchers whose proposed use of the data for a specific purpose has been approved.

\section{Patient and public involvement}

Patients or the public were not involved in the design, or conduct, reporting or dissemination plans of our research. 
Table 2 Haemodynamic parameters

\begin{tabular}{|c|c|c|c|c|}
\hline & All & Event (+) & Event (-) & $P$ value \\
\hline \multicolumn{5}{|c|}{ Rest echocardiographic variables } \\
\hline LVEDVi, mL/m² & $49 \pm 11$ & $49 \pm 14$ & $49 \pm 10$ & 0.87 \\
\hline LVESVi, $\mathrm{mL} / \mathrm{m}^{2}$ & $17 \pm 4$ & $17 \pm 6$ & $17 \pm 4$ & 0.59 \\
\hline LVEF, \% & $65 \pm 4$ & $66 \pm 3$ & $65 \pm 4$ & 0.15 \\
\hline LVMi, $g / \mathrm{m}^{2}$ & $75 \pm 17$ & $72 \pm 19$ & $76 \pm 16$ & 0.31 \\
\hline LAVi, $\mathrm{mL} / \mathrm{m}^{2}$ & $29 \pm 9$ & $29 \pm 12$ & $28 \pm 9$ & 0.79 \\
\hline $\mathrm{e}^{\prime}, \mathrm{cm} / \mathrm{s}$ & $10 \pm 3$ & $11 \pm 3$ & $10 \pm 3$ & 0.27 \\
\hline$E / e^{\prime}$ & $7 \pm 3$ & $8 \pm 4$ & $7 \pm 3$ & 0.09 \\
\hline RVEDA, $\mathrm{cm}^{2}$ & $14 \pm 3$ & $13 \pm 3$ & $14 \pm 3$ & 0.10 \\
\hline RVESA, $\mathrm{cm}^{2}$ & $8 \pm 2$ & $8 \pm 2$ & $8 \pm 2$ & 0.78 \\
\hline RVFAC, $\%$ & $44 \pm 10$ & $41 \pm 12$ & $45 \pm 10$ & 0.14 \\
\hline TAPSE, mm & $22 \pm 4$ & $21 \pm 4$ & $22 \pm 4$ & 0.50 \\
\hline $\mathrm{GLS}, \%$ & $19 \pm 3$ & $18 \pm 2$ & $19 \pm 3$ & 0.19 \\
\hline RVLS, \% & $25 \pm 6$ & $25 \pm 7$ & $25 \pm 6$ & 0.87 \\
\hline \multicolumn{5}{|l|}{ Exercise haemodynamics } \\
\hline Mean PAP, $\mathrm{mm} \mathrm{Hg}$ & $17 \pm 3$ & $18 \pm 3$ & $17 \pm 3$ & 0.29 \\
\hline Mean PAWP, & $11 \pm 4$ & $12 \pm 4$ & $11 \pm 4$ & 0.09 \\
\hline $\mathrm{CO}, \mathrm{L} / \mathrm{min}$ & $3.8 \pm 1.2$ & $4.1 \pm 1.7$ & $3.8 \pm 1.1$ & 0.41 \\
\hline PVR, wood unit & $1.9 \pm 1.1$ & $1.9 \pm 0.8$ & $1.9 \pm 1.2$ & 0.57 \\
\hline Exercise mean PAP, mm Hg & $23 \pm 5$ & $25 \pm 4$ & $23 \pm 5$ & 0.05 \\
\hline Exercise mean PAWP, $\mathrm{mm} \mathrm{Hg}$ & $13 \pm 4$ & $14 \pm 5$ & $12 \pm 4$ & 0.04 \\
\hline Exercise $\mathrm{CO}, \mathrm{L} / \mathrm{min}$ & $6.1 \pm 2.1$ & $5.6 \pm 2.1$ & $6.2 \pm 2.1$ & 0.19 \\
\hline Exercise PVR, wood unit & $1.9 \pm 1.0$ & $2.2 \pm 1.1$ & $1.9 \pm 0.9$ & 0.17 \\
\hline$\Delta \mathrm{mPAP} / \Delta \mathrm{CO}, \mathrm{mm} \mathrm{Hg} / \mathrm{L} / \mathrm{min}$ & $4.1 \pm 2.5$ & $8.9 \pm 3.8$ & $3.0 \pm 1.7$ & 0.008 \\
\hline$\triangle \mathrm{mPAWP} / \triangle \mathrm{CO}, \mathrm{mm} \mathrm{Hg} / \mathrm{L} / \mathrm{min}$ & $1.1 \pm 0.6$ & $2.2 \pm 0.9$ & $0.9 \pm 0.5$ & 0.004 \\
\hline$\Delta \mathrm{e}^{\prime}, \mathrm{cm} / \mathrm{s}$ & $0.9 \pm 3.1$ & $0.5 \pm 3.6$ & $1.0 \pm 3.1$ & 0.63 \\
\hline
\end{tabular}

Data are presented as number of patients (percentage) and mean $\pm \mathrm{SD}$.

$\mathrm{CO}$, cardiac output; e', early diastolic mitral annular motion; E, early diastolic transmitral flow velocity; LAVi, left atrial volume index; LVEDVi, left ventricular enddiastolic volume index; LVEF, left ventricular ejection fraction; LVESVi, left ventricular end-systolic volume index; LVMi, left ventricular mass index; mPAP, mean pulmonary artery pressure; mPAWP, mean pulmonary artery wedge pressure; PVR, pulmonary vascular resistance; RVEA, right ventricular end-diastolic area; RVESA, right ventricular end-systolic area; RVFAC, right ventricular functional area change; TAPSE, tricuspid annular plane systolic excursion.

\section{Study population}

We prospectively enrolled consecutive patients with SSc who underwent 6MW stress echocardiographic studies and had normal range of estimated mean pulmonary arterial pressure (mPAP) $(<25 \mathrm{~mm} \mathrm{Hg})$ and normal range of estimated mPAWP $(<15 \mathrm{~mm} \mathrm{Hg})$ at rest. Patients were referred to our echocardiographic examination centre between January 2014 and December 2018. Definitions of SSc were based on the American College of Rheumatology diagnostic criteria. ${ }^{11}$ Disease duration was defined as time from diagnosis to baseline echocardiography, and the observation period as time from baseline echocardiography to date of death or study end (December 2019). Figure 1 shows a selection of eligible patients and the enrolment process. Forty-nine patients at rest or during stress test were excluded due to incomplete measurable echocardiographic parameters (lack of tricuspid regurgitant velocity; $n=26$, lack of mitral annular velocity; $n=20$, and poor image quality; $\mathrm{n}=3$ ). We also excluded patients treated with PAHspecific therapies at baseline $(n=8)$, with moderate or severe valvular disease $(n=2)$, atrial fibrillation/flutter $(n=3)$, left ventricular ejection fraction $<50 \% \quad(n=2)$. One hundred forty patients fulfilled all criteria for the final analysis.

\section{Echocardiographic assessment}

Transthoracic echocardiography was performed by experienced sonographers/doctors using a commercially available ultrasound machine (Vivid 9, GE Vingmed, Horten, Norway). Measurements and recordings were obtained according to the American Society of Echocardiography recommendations. ${ }^{12}$ Systolic PAP was measured from the maximal continuous-wave Doppler velocity of the tricuspid regurgitant jet using systolic trans-tricuspid pressure gradient calculated by the modified Bernoulli equation. Right atrial pressure was estimated from the inferior vena cava diameter and collapsibility. ${ }^{13}$ The mPAP was calculated as $0.6 \times$ systolic $\mathrm{PAP}+2 .{ }^{14}$ The mPAWP was calculated as $1.24 \times\left(\mathrm{E} / \mathrm{e}^{\prime}\right)+1.9$ using the Nagueh formula. ${ }^{15}$ Pulmonary vascular resistance (PVR) was calculated as (mPAP-mPAWP)/CO. 


\begin{tabular}{|c|c|c|c|}
\hline & \multicolumn{3}{|c|}{ Univariate model } \\
\hline & HR & $95 \% \mathrm{Cl}$ & $P$ value \\
\hline Age & 1.02 & 0.98 to 1.05 & 0.54 \\
\hline Male, $\%$ & 0.41 & 0.01 to 9.17 & 0.25 \\
\hline Disease duration & 0.99 & 0.99 to 1.01 & 0.75 \\
\hline $\mathrm{HR}, \mathrm{bpm}$ & 1.00 & 0.97 to 1.04 & 0.87 \\
\hline Systolic BP, mm Hg & 0.99 & 0.98 to 1.02 & 0.72 \\
\hline $\mathrm{SpO}_{2}, \%$ & 0.93 & 0.73 to 1.19 & 0.57 \\
\hline \multicolumn{4}{|c|}{ Rest echocardiographic variables } \\
\hline LVEF, \% & 1.01 & 0.95 to 1.07 & 0.86 \\
\hline LAVi, $\mathrm{mL} / \mathrm{m}^{2}$ & 1.01 & 0.97 to 1.05 & 0.73 \\
\hline $\mathrm{E} / \mathrm{e}^{\prime}$ & 1.09 & 1.01 to 1.19 & 0.04 \\
\hline GLS & 0.88 & 0.71 to 1.10 & 0.26 \\
\hline RVLS & 0.97 & 0.87 to 1.09 & 0.67 \\
\hline \multicolumn{4}{|l|}{ Exercise haemodynamics } \\
\hline mPAP, mm Hg & 1.09 & 0.95 to 1.26 & 0.22 \\
\hline mPAWP, mm Hg & 1.07 & 1.00 to 1.15 & 0.04 \\
\hline $\mathrm{CO}, \mathrm{L} / \mathrm{min}$ & 1.14 & 0.84 to 1.55 & 0.41 \\
\hline Exercise mPAP, mm Hg & 1.06 & 1.00 to 1.13 & 0.07 \\
\hline Exercise mPAWP, mm Hg & 1.08 & 1.02 to 1.15 & 0.012 \\
\hline Exercise $\mathrm{CO}, \mathrm{L} / \mathrm{min}$ & 0.84 & 0.66 to 1.06 & 0.14 \\
\hline$\triangle \mathrm{mPAWP}$ & 1.27 & 1.01 to 1.61 & 0.049 \\
\hline$\Delta \mathrm{CO}$ & 0.58 & 0.38 to 0.87 & 0.009 \\
\hline$\Delta \mathrm{mPAP} / \Delta \mathrm{CO}, \mathrm{mm} \mathrm{Hg} / \mathrm{L} / \mathrm{min}$ & 1.06 & 1.02 to 1.10 & 0.002 \\
\hline$\Delta \mathrm{mPAWP} / \Delta \mathrm{CO}, \mathrm{mm} \mathrm{Hg} / \mathrm{L} / \mathrm{min}$ & 1.38 & 1.17 to 1.63 & $<0.001$ \\
\hline$\Delta \mathrm{e}^{\prime}, \mathrm{cm} / \mathrm{s}$ & 0.95 & 0.84 to 1.07 & 0.38 \\
\hline
\end{tabular}

$\mathrm{BP}$, blood pressure; $\mathrm{CO}$, cardiac output; \%DLCO, diffusing capacity for carbon monoxide; e', early diastolic mitral annular motion; $E$, early diastolic transmitral flow velocity; \%FEV1, percent forced expiratory volume in 1 s; \%FVC, percent forced vital capacity; HR, heart rate; LAVi, left atrial volume index; LVEDVi, left ventricular end-diastolic volume index; LVEF, left ventricular ejection fraction; LVESVi, left ventricular end-systolic volume index; LVMi, left ventricular mass index; MCTD, mixed connective tissue disease; mPAP, mean pulmonary artery pressure; mPAWP, mean pulmonary artery wedge pressure; PVR, pulmonary vascular resistance; RVEA, right ventricular end-diastolic area; RVESA, right ventricular end-systolic area; RVFAC, right ventricular functional area change; $\mathrm{SpO}_{2}$, percutaneous oxygen saturation; SSc, systemic sclerosis; TAPSE, tricuspid annular plane systolic excursion.

Peak systolic longitudinal strain measurements were obtained from greyscale images recorded in the apical 4-chamber, 2-chamber and long-axis views. The frame rate was maintained at $>40$ frame/s. All strains were analysed offline using speckle tracking vender-independent software (EchoInsight, Epsilon Imaging, Ann Arbor, Michigan, USA). Global longitudinal strain (GLS) was obtained by averaging all segmental strain values from the apical 4-chamber, 2-chamber and long-axis views. In RV longitudinal strain analysis from the RV focused apical 4-chamber view, the interventricular septum was included in the region-of-interest for speckle-tracking echocardiography, but only the free wall strain values were included and the septal strain values were discarded to avoid LV interaction. GLS and RV longitudinal strain were obtained at rest.

\section{Six-minute walk stress echocardiography}

Online supplemental clip shows the 6MW stress echocardiography. The $6 \mathrm{MW}$ tests were performed according to the American Thoracic Society guidelines. ${ }^{16}$ The transcutaneous arterial oxygen saturation was determined by pulse oximetry. As we performed in our previous study, ${ }^{9}$ post-6MW (within $30 \mathrm{~s}$ ), early diastolic transmitral flow/ annular velocity and the peak tricuspid regurgitation jet were obtained immediately. $\mathrm{CO}$ was also obtained from electric cardiometry (Aesculon Electrical Velocimetry, Osypka Medical GmbH, Berlin, Germany) at the same time in order to check the changes of CO immediately after the 6MW test. ${ }^{17}$ Because it was difficult to measure many indices immediately after the 6MW test, we used electric cardiometry to obtain $\mathrm{CO}$. We calculated the slope of $\mathrm{mPAWP} / \mathrm{CO}$ and $\mathrm{mPAP} / \mathrm{CO}$ in individual patients $(\Delta \mathrm{mPAWP} / \triangle \mathrm{CO}$ and $\Delta \mathrm{mPAP} / \Delta \mathrm{CO})$.

In 14 patients, exercise right heart catheterisation was performed using a Swan-Ganz catheter to assess the actual haemodynamics. Pressure measurements were obtained at rest and during supine bicycle ergometery. The workload was increased at $25 \mathrm{~W}$ increments every 3 min. Average peak workload was $50 \mathrm{~W}$ in our cohort. The following haemodynamic parameters were recorded at the peak workload: PAWP, mPAP and CO. Thermodilution $\mathrm{CO}$ were analysed after averaging the sum of three measurements at rest and during exercise.

\section{Clinical outcomes}

All patients were followed up at our hospital according to the research protocol (follow-up every 3 months). The composite outcome was time to clinical worsening, which was determined on the basis of time from baseline to the first occurrence of any of the following: cardiovascular death or unplanned hospitalisation for heart failure. Unplanned hospitalisation for heart failure was defined by an independent adjudicator as an overnight admission for heart failure (excluding emergency department only stays) which was not for an elective purpose or procedure. The duration of follow-up was begun at the time of the initial stress echocardiogram and ended in December 2019. The 6MW stress echocardiographic data were blinded to physicians at follow-up clinic after study initiation.

\section{Statistical analysis}

Data are presented as mean \pm SD. Statistical significance of differences between the groups was assessed using the Student's t-test for data with normal distribution, and the Mann-Whitney U test was used for data that were not normally distributed. For categorical variables, the Fisher's exact test was used. The association of clinical variables with outcome was identified by Cox proportional hazards models in univariate and multivariate analyses. A HR with a $95 \%$ CI was calculated for each variable. The scaled Schoenfeld residuals for each independent variable were plotted against time to assess the assumption of proportional hazards; these correlations were found 

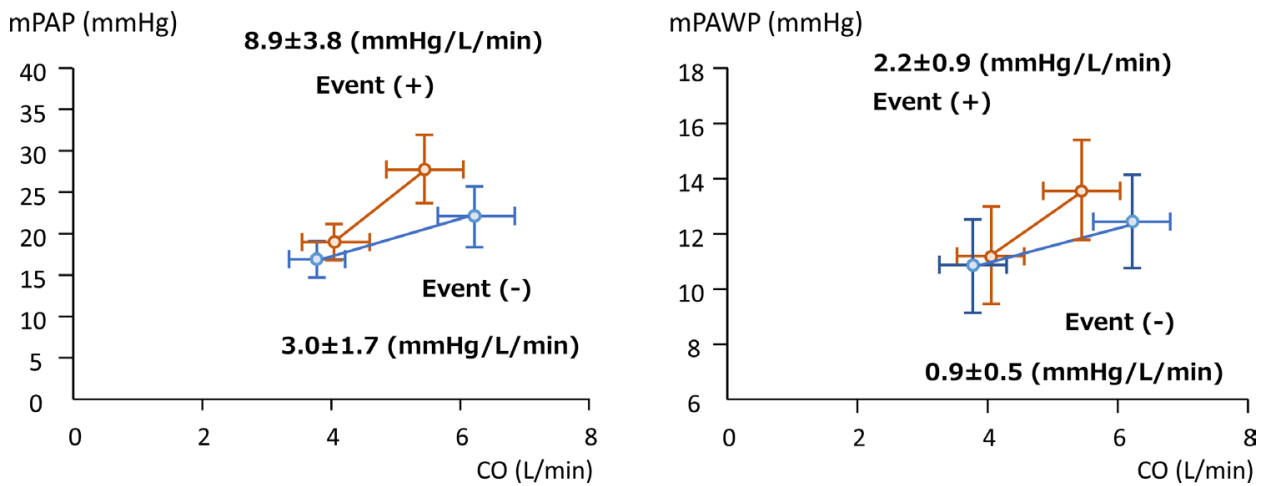

Figure 2 Multipoint for mPAWP-mPAP and cardiac output. (A) Multipoint mPAP-CO plots at baseline and post-6MW. $\triangle \mathrm{mPAP} /$ $\triangle \mathrm{CO}$ with events (the red line) is significantly greater than $\triangle \mathrm{mPAP} / \triangle \mathrm{CO}$ without events (the blue line) $(8.9 \pm 3.8 \mathrm{~mm} \mathrm{Hg} / \mathrm{L} / \mathrm{min} \mathrm{vs}$ $3.0 \pm 1.7 \mathrm{~mm} \mathrm{Hg} / \mathrm{L} / \mathrm{min} ; \mathrm{p}=0.002$ ). (B) Multipoint $\mathrm{mPAWP}-\mathrm{CO}$ plots at baseline and post-6MW. $\triangle \mathrm{mPAWP} / \triangle \mathrm{CO}$ with events (the red line) is significantly greater than $\triangle \mathrm{mPAWP} / \triangle \mathrm{CO}$ without events (the blue line) $(2.2 \pm 0.9 \mathrm{~mm} \mathrm{Hg} / \mathrm{L} / \mathrm{min}$ vs $0.9 \pm 0.5 \mathrm{~mm} \mathrm{Hg} / \mathrm{L} /$ min; $p<0.001$ ). $6 \mathrm{MW}, 6$-minute walk; $\mathrm{CO}$, cardiac output; mPAP, mean pulmonary artery pressure; mPAWP, mean pulmonary artery wedge pressure.

to be non-significant. Receiver operating characteristic (ROC) curves were generated to determine optimal cutoff values of continuous variables. The best cut-off value was defined as the upper limit of the CI of the Youden index. To assess prognostic value, reference values of $\Delta \mathrm{mPAP} / \Delta \mathrm{CO}(3.0 \mathrm{~mm} \mathrm{Hg} / \mathrm{L} / \mathrm{min}$ based on our previous paper $)^{9}$ and $\Delta \mathrm{mPAWP} / \Delta \mathrm{CO}(1.4 \mathrm{~mm} \mathrm{Hg} / \mathrm{L} / \mathrm{min}$ based on ROC analysis) were used to divide patients into two groups for Kaplan-Meier analysis, with event-free survival compared using a two-sided log-rank test. Statistical analysis was performed using standard statistical software packages (SPSS software V.21.0, SPSS; MedCalc software V.17; Mariakerke, Belgium). Statistical significance was defined by $\mathrm{p}<0.05$.

\section{RESULTS}

\section{Patient characteristics}

Baseline characteristics of the study group are presented in table 1 . The study population consisted of 140 patients $(61 \pm 12$ years; $10 \%$ male) who underwent $6 \mathrm{MW}$ stress echocardiography. Those patients were divided into two groups with and without events. Both study groups had short disease duration (1.5 and 1.7 months, respectively). Also, complications such as respiratory dysfunction or abnormal haemodynamics at baseline (eg, ischaemic heart disease, heart failure, atrial fibrillation, hypertension) were not present in either group, thus no medication treating common complications of SSc was administrated when the 6MW test was performed. Heart rate and blood pressure at baseline were well-controlled in this cohort (heart rate: $68 \pm 12$ beats/min and systolic blood pressure: $123 \pm 20 \mathrm{~mm} \mathrm{Hg}$ ). Post- $6 \mathrm{MW}$, heart rate and blood pressure were increased, and percutaneous oxygen saturation was slightly decreased. The correlation between invasive and non-invasive (electric cardiometry and echocardiography) values is shown in online supplemental figure 1. The invasive data are shown in online supplemental table 1. In this small cohort, there was a good correlation between invasive and non-invasive of $\Delta \mathrm{mPAWP} / \Delta \mathrm{CO}$ $(\mathrm{r}=0.78 ; \mathrm{p}<0.001)$. The intraobserver variability for the measurement of $\triangle \mathrm{mPAWP} / \Delta \mathrm{CO}$ was $6.5 \% \pm 2.8 \%$; interobserver variability was $8.2 \% \pm 4.6 \%$. Echocardiographic variables are shown in table 2 . Post-6MW, CO, mPAP and mPAWP were increased. The average $\triangle \mathrm{PAWP} / \triangle \mathrm{CO}$ was $1.1 \pm 0.6 \mathrm{~mm} \mathrm{Hg} / \mathrm{L} / \mathrm{min}$ and the average $\Delta \mathrm{mPAP} / \Delta \mathrm{CO}$ was $4.1 \pm 2.5 \mathrm{~mm} \mathrm{Hg} / \mathrm{L} / \mathrm{min}$. There was no difference in PVR between event $(+)$ and event (-) groups in the resting and exercise states.

\section{Event-free survival}

During a median period of 3.6 years (IQR 2.0-5.1 years), 25 patients $(18 \%)$ reached the composite outcome (cardiovascular death due to heart failure, $\mathrm{n}=1$; unplanned hospitalisation for heart failure, $n=24$ ). HRs of the relevant parameters in univariate models are shown in table 3. At rest parameters, E/e' (HR 1.09; 95\% CI 1.01 to $1.19, \mathrm{p}=0.04$ ) and mPAWP (HR 1.07; $95 \%$ CI 1.00 to $1.15 ; \mathrm{p}=0.04)$ were associated with time to clinical worsening. At exercise parameters, the exercise mPAWP (HR $1.08 ; 95 \%$ CI 1.02 to $1.15, \mathrm{p}=0.012$ ), $\Delta \mathrm{mPAP} / \Delta \mathrm{CO}$ (HR $1.06 ; 95 \%$ CI 1.02 to $1.10, \mathrm{p}=0.002)$ and $\Delta \mathrm{mPAWP} / \Delta \mathrm{CO}$ (HR $1.38 ; 95 \%$ CI 1.17 to 1.63 , $\mathrm{p}<0.001$ ) were associated with time to clinical worsening. In addition, $\Delta \mathrm{CO}$ was also associated with adverse outcomes (HR $0.58 ; 95 \%$ CI 0.38 to $0.87, \mathrm{p}=0.009$ ). Figure 2 shows multipoint mPAWP-CO plots and mPAP-CO plots at baseline and post-6MW. The $\Delta \mathrm{mPAP} / \triangle \mathrm{CO}$ in patients with events was significantly greater than in patients without events $(8.9 \pm 3.8$ $\mathrm{mm} \mathrm{Hg} / \mathrm{L} / \mathrm{min}$ vs $3.0 \pm 1.7 \mathrm{~mm} \mathrm{Hg} / \mathrm{L} / \mathrm{min} ; \mathrm{p}=0.002$ ). Moreover, the $\triangle \mathrm{mPAWP} / \triangle \mathrm{CO}$ in patients with events was also significantly greater than in patients without events $(2.2 \pm 0.9 \mathrm{~mm} \mathrm{Hg} / \mathrm{L} / \mathrm{min}$ vs $0.9 \pm 0.5 \mathrm{~mm} \mathrm{Hg} / \mathrm{L} / \mathrm{min}$; $\mathrm{p}<0.001)$. Using an ROC curve, we found that the best cut-off value of $\triangle \mathrm{mPAWP} / \triangle \mathrm{CO}$ for predicting events was $>1.4 \mathrm{~mm} \mathrm{Hg} / \mathrm{L} / \mathrm{min}$ with $60 \%$ sensitivity and $80 \%$ specificity.

In the multivariate model, $\Delta \mathrm{mPAP} / \Delta \mathrm{CO}, \Delta \mathrm{mPAWP} /$ $\Delta \mathrm{CO}$ and their interaction were selected to test the 


\begin{tabular}{lllc}
\hline Table 4 & Multivariate associations of outcomes \\
\hline & \multicolumn{4}{c}{ Multivariate model } \\
\cline { 2 - 4 } & HR & $\mathbf{9 5 \%}$ Cl & P value \\
\hline$\Delta \mathrm{mPAP} / \Delta C 0, \mathrm{~mm} \mathrm{Hg} / \mathrm{L} / \mathrm{min}$ & 1.18 & 1.05 to 1.32 & 0.006 \\
$\Delta \mathrm{mPAWP} / \Delta \mathrm{CO}, \mathrm{mm} \mathrm{Hg} / \mathrm{L} / \mathrm{min}$ & 2.12 & 1.46 to 3.06 & $<0.001$ \\
$\Delta \mathrm{mPAP} / \triangle \mathrm{CO} \times \Delta \mathrm{mPAWP} / \Delta \mathrm{CO}$ & 0.96 & 0.93 to 0.99 & 0.016 \\
\hline
\end{tabular}

$\mathrm{CO}$, cardiac output; mPAP, mean pulmonary artery pressure; mPAWP, mean pulmonary artery wedge pressure.;

clinical utility of these variables (table 4). Interestingly, $\Delta \mathrm{mPAP} / \triangle \mathrm{CO}$ (HR $1.18 ; 95 \%$ CI 1.05 to $1.32, \mathrm{p}=0.006$ ), $\Delta \mathrm{mPAWP} / \Delta \mathrm{CO}$ (HR 2.12; $95 \%$ CI 1.46 to $3.06, \mathrm{p}<0.001$ ) and their interaction (HR $0.96 ; 95 \%$ CI 0.93 to 0.99 , $\mathrm{p}=0.016$ ) were significantly associated with time to clinical worsening. Figure 3 illustrates patient time to event stratified according to $\triangle \mathrm{mPAP} / \triangle \mathrm{CO}$ and $\Delta \mathrm{mPAWP} / \Delta \mathrm{CO}$ to check the influence of this interaction. Patients with impaired pulmonary vascular $(\mathrm{PV})$ reserve $(\triangle \mathrm{mPAP} /$ $\Delta \mathrm{CO}>3.0 \mathrm{~mm} \mathrm{Hg} / \mathrm{L} / \mathrm{min})$ and impaired $\mathrm{LV}$ cardiac reserve $(\Delta \mathrm{mPAWP} / \Delta \mathrm{CO}>1.4 \mathrm{~mm} \mathrm{Hg} / \mathrm{L} / \mathrm{min})$ had significantly shorter event-free survival than those without these abnormalities.

Table 5 shows the clinical characteristics and haemodynamic variables in categorised groups by $\mathrm{LV}$ and $\mathrm{PV}$ reserve. There was no difference in haemodynamic parameters at rest among the groups. On the other hand, exercise haemodynamic parameters were significantly different compared with normal LV and PV reserve in the other groups. In univariate Cox proportional hazard analysis, the HRs for each group of LV and PV reserve using the normal LV and PV groups as a reference are shown in table 5. Patients with impaired PV reserve and $\mathrm{LV}$ reserve had the highest risk for outcomes among the groups (HR 35.4; $95 \%$ CI 4.6 to $271, \mathrm{p}<0.05$ ).

\section{DISCUSSION}

Our study brings several new insights into the understanding of cardiac and pulmonary functions in patients with SSc: (1) The $\Delta \mathrm{mPAP} / \Delta \mathrm{CO}$ and $\Delta \mathrm{mPAWP} / \Delta \mathrm{CO}$ in the event group was significantly increased compared with that of the non-event group. (2) Impaired LV cardiac reserve and PV reserve were independent predictors of clinical worsening. (3) There was good correlation between echocardiography-based parameters after 6MW testing and catheter-based parameters during ergometer stress. We believe that the reliability of the 6MW stress echocardiography is acceptable in this cohort. Those results indicated that a 6MW stress echocardiographic study may predict a high-risk group in patients with SSc, even within 3 months after diagnosis. The invasive measurements were made during peak exercise load during ergometric testing, a good correlation may be helpful to convince those who are concerned about the reliability of the 6MW echo test, where measurements are performed after the exercise.

\section{Diastolic dysfunction in sclerosis}

Recently, there has been focused discussion on the importance of LVDD in SSc. Previous studies demonstrated that LVDD has a high prevalence and may be an independent predictor of mortality in SSc. ${ }^{18}$ Although diastolic dysfunction is often one of the earliest signs of cardiac impairment in SSc, it is not always manifested in

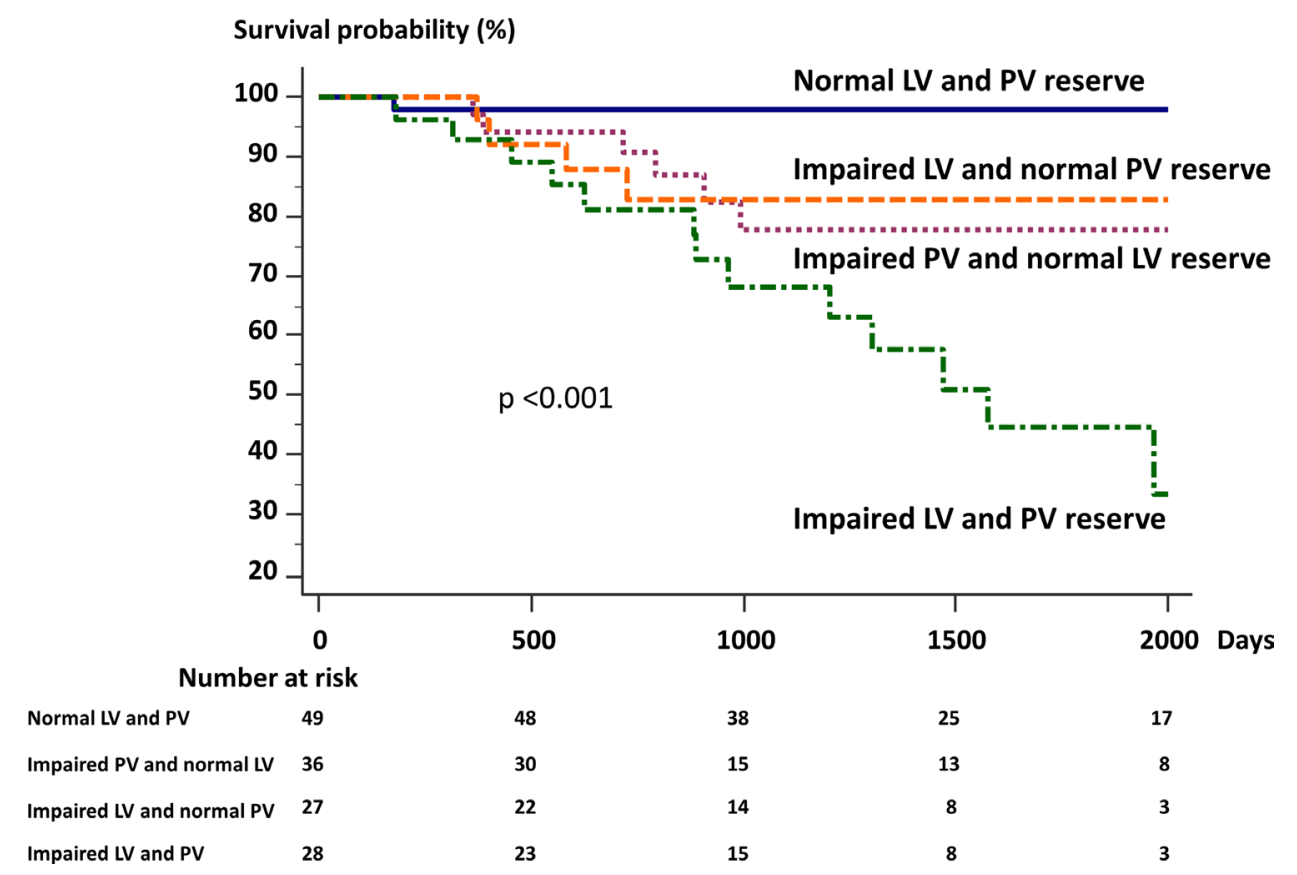

Figure 3 Kaplan-Meier analysis of event-free survival. Patients were stratified according to pulmonary vascular (PV) reserve $(\triangle \mathrm{mPAP} / \triangle \mathrm{CO})$ and left ventricular $(\mathrm{LV})$ cardiac reserve $(\triangle \mathrm{mPAWP} / \triangle \mathrm{CO})$. Patients with abnormal $\Delta \mathrm{mPAP} / \triangle \mathrm{CO}(>3.0 \mathrm{~mm} \mathrm{Hg} / \mathrm{L} /$ $\mathrm{min})$ or $\triangle \mathrm{mPAWP} / \triangle \mathrm{CO}(>1.4 \mathrm{~mm} \mathrm{Hg} / \mathrm{L} / \mathrm{min})$ are strongly associated with shorter event-free survival. Moreover, patients with both impaired LV and PV function had worst outcomes. 
Table 5 Clinical characteristics in categorised groups by LV and PV reserve

\begin{tabular}{|c|c|c|c|c|}
\hline & Norma LV and PV reserve & $\begin{array}{l}\text { Impaired PV and } \\
\text { normal LV reserve }\end{array}$ & $\begin{array}{l}\text { Impaired LV and } \\
\text { normal PV reserve }\end{array}$ & $\begin{array}{l}\text { Impaired } L V \text { and } P V \\
\text { reserve }\end{array}$ \\
\hline Number & 49 & 36 & 27 & 28 \\
\hline Male, $\%$ & $5(10)$ & $6(17)$ & $1(4)$ & $2(7)$ \\
\hline \multicolumn{5}{|c|}{ Rest echocardiographic variables } \\
\hline LVEDVi, $\mathrm{mL} / \mathrm{m}^{2}$ & $50 \pm 10$ & $50 \pm 14$ & $48 \pm 11$ & $48 \pm 9$ \\
\hline LVEF, \% & $65 \pm 4$ & $66 \pm 3$ & $64 \pm 3$ & $66 \pm 4$ \\
\hline LVMi, $g / \mathrm{m}^{2}$ & $76 \pm 17$ & $76 \pm 15$ & $74 \pm 20$ & $74 \pm 15$ \\
\hline LAVi, $\mathrm{mL} / \mathrm{m}^{2}$ & $27 \pm 8$ & $27 \pm 10$ & $32 \pm 7$ & $29 \pm 11$ \\
\hline $\mathrm{e}^{\prime}, \mathrm{cm} / \mathrm{s}$ & $11 \pm 3$ & $11 \pm 3$ & $10 \pm 2$ & $10 \pm 3$ \\
\hline$E / e^{\prime}$ & $6 \pm 2$ & $8 \pm 3$ & $8 \pm 4$ & $7 \pm 3$ \\
\hline GLS, $\%$ & $19 \pm 2$ & $19 \pm 4$ & $19 \pm 2$ & $19 \pm 3$ \\
\hline RVLS, \% & $24 \pm 5$ & $26 \pm 6$ & $24 \pm 7$ & $25 \pm 7$ \\
\hline \multicolumn{5}{|l|}{ Exercise haemodynamics } \\
\hline Mean PAP, mm Hg & $17 \pm 2$ & $17 \pm 4$ & $18 \pm 2$ & $18 \pm 3$ \\
\hline Mean PAWP, $\mathrm{mm} \mathrm{Hg}$ & $10 \pm 2$ & $11 \pm 5$ & $12 \pm 4$ & $11 \pm 4$ \\
\hline $\mathrm{CO}, \mathrm{L} / \mathrm{min}$ & $3.9 \pm 1.1$ & $3.9 \pm 1.6$ & $3.7 \pm 1.0$ & $3.7 \pm 0.9$ \\
\hline PVR, wood unit & $1.9 \pm 0.9$ & $1.8 \pm 0.9$ & $1.8 \pm 0.8$ & $2.4 \pm 1.8$ \\
\hline Exercise mean PAP, mm Hg & $21 \pm 4$ & $24 \pm 5^{\star}$ & $21 \pm 3$ & $26 \pm 6^{*}$ \\
\hline Exercise mean PAWP, mm Hg & $11 \pm 3$ & $12 \pm 5$ & $15 \pm 4^{*}$ & $14 \pm 5^{\star}$ \\
\hline
\end{tabular}

*Versus normal LV and PV, p<0.05.

CO, cardiac output; e', early diastolic mitral annular motion; E, early diastolic transmitral flow velocity; LAVi, left atrial volume index; LVEDVi, left ventricular enddiastolic volume index; LVEF, left ventricular ejection fraction; LVESVi, left ventricular end-systolic volume index; LVMi, left ventricular mass index; mPAP, mean pulmonary artery pressure; mPAWP, mean pulmonary artery wedge pressure; PVR, pulmonary vascular resistance; RVEA, right ventricular end-diastolic area; RVESA, right ventricular end-systolic area; RVFAC, right ventricular functional area change; TAPSE, tricuspid annular plane systolic excursion.

a resting state. Nevertheless, the early stage of LVDD with normal resting haemodynamics can be diagnosed by an exercise stress test. The previous study found that exercise PAWP may be associated with outcome in early stage heart failure. ${ }^{19}$ Moreover, the E/e' exercise ratio correlated with LV filling pressure (eg, PAWP) and predicted adverse cardiovascular outcomes. ${ }^{20} 21$ Those reports are consistent with our analysis that exercise mPAWP calculated by the E/e' ratio is associated with adverse outcomes in our SSc group.

The balance of PAWP and CO is key to evaluate LVDD. As long as the Frank-Starling mechanism functions effectively, CO increases after dynamic preload stress; however, it does not apply to patients with severely impaired LV relaxation, which results in only slightly increased $\mathrm{CO}$ on significantly elevated PAWP. ${ }^{10}$ It has also been reported that decreased peak $\mathrm{CO}$ measured by an exercise stress test is associated with poor prognosis in congestive heart failure. $^{22}$ Those studies are compatible with our result, in which mPAWP/CO was increased after the 6MW test compared with resting, especially in the events group. In addition, among our small cohort, good correlation between the catheter and echocardiography of $\Delta \mathrm{mPAWP} / \triangle \mathrm{CO}$ was observed at rest and during exercise. It indicates that the $6 \mathrm{MW}$ stress echocardiographic study is useful to detect early LVDD without invasive measurement and to predict outcome in patients with SSc despite normal resting haemodynamics.

\section{Pulmonary vascular function in sclerosis}

$\mathrm{PH}$ is a severe complication of SSc, and currently early detection and management of PAH is recommended. ${ }^{23}$ $\Delta \mathrm{mPAP} / \triangle \mathrm{CO}$ with $6 \mathrm{MW}$ stress echocardiography has been shown to be a good predictor of $\mathrm{PH}$ development 
in connective tissue diseases including SSc. ${ }^{9}$ Our results confirmed that $\triangle \mathrm{mPAP} / \Delta \mathrm{CO}$ measured by the $6 \mathrm{MW}$ test predicts a worse outcome in patients with SSc. However, the possibility remains that LVDD leads to an elevated left atrial pressure, resulting in PH (WHO Group 2) which affects prognosis. In fact, it has been reported that $\mathrm{PH}$ related to SSc can sometimes be associated with occult left-sided diastolic dysfunction. ${ }^{24}$ Also, SSc patients with PH due to early LVDD showed a twofold increased risk of death, compared with isolated patients with SScPAH. ${ }^{25}$ Furthermore, LVDD might affect mortality independently in patients with SSc. Thus, the assessment of both PV function and early diastolic dysfunction is necessary to measure the prognosis of patients with SSc. In addition, the RV-PA coupling index may be useful as an early prognostic indicator in early SSc. ${ }^{26}$ It could be an important indicator in this area in the future.

In our analysis, although most of the resting echocardiographic measurements, including GLS and RVLS, did not have predictive values in SSc, the value of $6 \mathrm{MW}$ stress echocardiography related to clinical worsening in both $\mathrm{LV}$ cardiac reserve $(\triangle \mathrm{mPAWP} / \Delta \mathrm{CO})$ and $\mathrm{PV}$ reserve $(\Delta \mathrm{mPAP} / \Delta \mathrm{CO})$. Importantly, $\mathrm{CO}$ change was a more prominent factor associated with adverse outcomes in univariate analysis. $\mathrm{CO}$ is a key diagnostic parameter and a major prognostic factor in PAH. We should take $\mathrm{CO}$ into account when we assess pulmonary artery pressure. In the setting of impaired PV reserve, 6MW stress echocardiography revealed that SSc patients with LVDD had worse prognoses than those without LVDD, consistent with previous studies. Interestingly, in the setting of normal PV reserve, SSc patients with LVDD had worse prognosis than those without LVDD. These results indicate that impaired LV cardiac reserve in SSc, enhanced by 6MW stress echocardiography, can be an independent prognostic factor prior to development of complications, including PH, or treatment, since our cohort was examined at an initial naïve state. Therefore, it is essential to assess LV function as soon as SSc is diagnosed.

\section{Clinical implications}

It is clinically important to monitor high-risk patients and treat those who show an abnormal pulmonary arterial bed. Figure 4 shows a potential approach to exercise haemodynamics in SSc. The 6MW stress echocardiography should be considered to assess PV and LV cardiac reserve and used as a guide for definition in this high-risk cohort.

\section{Limitations}

This is a single centre study that included a selected patient population. The data are a little limited by a large number of patients early in the study without useable echocardiographic data. ${ }^{27-29}$ Early in the study, many patients had incomplete echocardiographic study data (2014-2016: $\mathrm{n}=37,2017-2018: \mathrm{n}=12$ ). Possibly the amount of missing data decreased as the observers gained experience. A major reason for incomplete echocardiography was

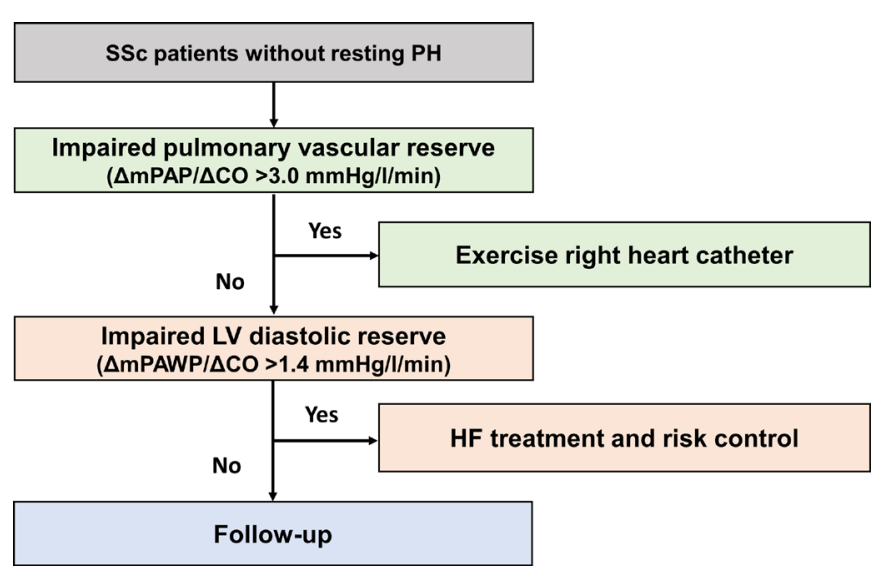

Figure 4 Potential approach to exercise haemodynamics in systemic sclerosis (SSc). We propose a potential approach to identify a high-risk group in SSc. CO, cardiac output; mPAP, mean pulmonary artery pressure; mPAWP, mean pulmonary artery wedge pressure.

missing tricuspid regurgitant velocity $(65 \%)$. In this test, observers must check the tricuspid regurgitant jet using multiplane scanning and arrange the machine setting, including the velocity range to overcome this issue. The $6 \mathrm{MW}$ test does not require any equipment such as an ergometer, and exercise tolerance can be assessed by the 6MW distance. This method is cost-effective and simple to screen in SSc anywhere. Our outcomes had relatively soft endpoints because we focused on the very early stage of cardiac dysfunction in patients with SSc who have, in general, few hard endpoints. Previous data showed a linearity in $\triangle \mathrm{mPAP} / \triangle \mathrm{CO}$; however, there were limited data on this physiology. ${ }^{30}$ With these limitations, we believe that larger prospective multicentre studies are warranted.

\section{CONCLUSIONS}

Impairments in both the PV and the LV reserve assessed by $6 \mathrm{MW}$ stress echocardiography were associated with significant increase in the risk of the composite event (heart failure hospitalisation and cardiovascular death). Thus, $6 \mathrm{MW}$ stress echocardiography can be applied to treat naïve patients with SSc.

Acknowledgements The authors acknowledge Kathryn Brock, BA, for editing the manuscript.

Contributors Design of the work: MA, KK and MS. Conduct of the work and data acquisition: SM, NY, YH, SN, TI, TT, KY, DF, SY, HY, TS and TW. Data analysis and interpretation: MA, KK and MS. Drafting the work: MA, KK and MS. Reviewing the work and providing input: all authors. Final approval: all authors.

Funding This work was supported by the Japan Society for the Promotion of Science Kakenhi Grants (Number 20K17084 to Y0), Takeda Science Foundation (to KK), Public Trust Cardiovascular Research Fund (to KK), and Japan Agency for Medical Research and Development under Grant Number JP19lk1010035 to KK.

Disclaimer The funding source had no role in the design and conduct of the study; collection, management, analysis and interpretation of the data; preparation, review or approval of the manuscript; and decision to submit the manuscript for publication.

Competing interests None declared.

Patient consent for publication Not required. 
Ethics approval This study was approved by the local ethics committee and Institutional Review Board (protocol: 1095-2)

Provenance and peer review Not commissioned; externally peer reviewed.

Data availability statement The individual anonymised data supporting the analyses contained in the manuscript will be made available upon reasonable written request from researchers whose proposed use of the data for a specific purpose has been approved.

Open access This is an open access article distributed in accordance with the Creative Commons Attribution 4.0 Unported (CC BY 4.0) license, which permits others to copy, redistribute, remix, transform and build upon this work for any purpose, provided the original work is properly cited, a link to the licence is given, and indication of whether changes were made. See: https://creativecommons.org/ licenses/by/4.0/.

\section{ORCID iDs}

Kenya Kusunose http://orcid.org/0000-0002-4909-754X

Hirotsugu Yamada http://orcid.org/0000-0003-3741-5560

\section{REFERENCES}

1 Smith V, Scirè CA, Talarico R, et al. Systemic sclerosis: state of the art on clinical practice guidelines. RMD Open 2019;4:e000782.

2 Lambova S. Cardiac manifestations in systemic sclerosis. World J Cardiol 2014;6:993.

3 Parks JL, Taylor MH, Parks LP, et al. Systemic sclerosis and the heart. Rheum Dis Clin North Am 2014;40:87-102.

4 Ferri C, Giuggioli D, Sebastiani M, et al. Heart involvement and systemic sclerosis. Lupus 2005;14:702-7.

5 Hinchcliff M, Desai CS, Varga J, et al. Prevalence, prognosis, and factors associated with left ventricular diastolic dysfunction in systemic sclerosis. Clin Exp Rheumatol 2012;30:S30.

6 Faludi R, Költő G, Bartos B, et al. Five-Year follow-up of left ventricular diastolic function in systemic sclerosis patients: determinants of mortality and disease progression. Semin Arthritis Rheum 2014;44:220-7.

7 Tennøe AH, Murbræch K, Andreassen JC, et al. Left ventricular diastolic dysfunction predicts mortality in patients with systemic sclerosis. J Am Coll Cardiol 2018;72:1804-13.

8 Borlaug BA, Nishimura RA, Sorajja P, et al. Exercise hemodynamics enhance diagnosis of early heart failure with preserved ejection fraction. Circ Heart Fail 2010;3:588-95.

9 Kusunose K, Yamada H, Hotchi J, et al. Prediction of future overt pulmonary hypertension by 6 -min walk stress echocardiography in patients with connective tissue disease. J Am Coll Cardiol 2015;66:376-84.

10 Kusunose K. Clinical application of stress echocardiography in management of heart failure. Heart Fail Clin 2020;16:347-55.

11 Hochberg MC. Updating the American College of rheumatology revised criteria for the classification of systemic lupus erythematosus. Arthritis Rheum 1997;40:40.

12 Lang RM, Badano LP, Mor-Avi V, et al. Recommendations for cardiac chamber quantification by echocardiography in adults: an update from the American Society of echocardiography and the European association of cardiovascular imaging. J Am Soc Echocardiogr 2015;28:e14:1-39.

13 Milan A, Magnino C, Veglio F. Echocardiographic indexes for the non-invasive evaluation of pulmonary hemodynamics. J Am Soc Echocardiogr 2010;23:225-39.
14 Chemla D, Castelain V, Humbert M, et al. New formula for predicting mean pulmonary artery pressure using systolic pulmonary artery pressure. Chest 2004;126:1313-7.

15 Nagueh SF, Middleton KJ, Kopelen HA, et al. Doppler tissue imaging: a noninvasive technique for evaluation of left ventricular relaxation and estimation of filling pressures. J Am Coll Cardiol 1997;30:1527-33.

16 ATS Committee on Proficiency Standards for Clinical Pulmonary Function Laboratories. Ats statement: guidelines for the six-minute walk test. Am J Respir Crit Care Med 2002;166:111-7.

17 Bernstein DP. A new stroke volume equation for thoracic electrical bioimpedance: theory and rationale. Crit Care Med 1986;14:904-9.

18 Steen VD, Medsger TA. Severe organ involvement in systemic sclerosis with diffuse scleroderma. Arthritis Rheum 2000;43:2437-44.

19 Mascherbauer J, Zotter-Tufaro C, Duca F, et al. Wedge pressure rather than left ventricular end-diastolic pressure predicts outcome in heart failure with preserved ejection fraction. JACC Heart Fail 2017;5:795-801.

20 Burgess MI, Jenkins C, Sharman JE, et al. Diastolic stress echocardiography: hemodynamic validation and clinical significance of estimation of ventricular filling pressure with exercise. J Am Coll Cardiol 2006;47:1891-900.

21 Holland DJ, Prasad SB, Marwick TH. Prognostic implications of left ventricular filling pressure with exercise. Circ Cardiovasc Imaging 2010;3:149-56.

22 Williams SG, Cooke GA, Wright DJ, et al. Peak exercise cardiac power output; a direct indicator of cardiac function strongly predictive of prognosis in chronic heart failure. Eur Heart $J$ 2001;22:1496-503.

23 Galiè N, Humbert M, Vachiery J-L, et al. 2015 ESC/ERS guidelines for the diagnosis and treatment of pulmonary hypertension: the joint Task force for the diagnosis and treatment of pulmonary hypertension of the European Society of cardiology (ESC) and the European respiratory Society (ERS): endorsed by: association for European paediatric and congenital cardiology (AEPC), International Society for heart and lung transplantation (ISHLT). Eur Heart $J$ 2016;37:67-119.

24 Fox BD, Shimony A, Langleben D, et al. High prevalence of occult left heart disease in scleroderma-pulmonary hypertension. Eur Respir J 2013;42:1083-91.

25 Bourji KI, Kelemen BW, Mathai SC, et al. Poor survival in patients with scleroderma and pulmonary hypertension due to heart failure with preserved ejection fraction. Pulm Circ 2017;7:409-20.

26 Tello K, Dalmer A, Axmann J, et al. Reserve of right ventriculararterial coupling in the setting of chronic overload. Circ Heart Fail 2019;12:e005512.

27 Argiento P, Vanderpool RR, Mulè M, et al. Exercise stress echocardiography of the pulmonary circulation: limits of normal and sex differences. Chest 2012;142:1158-65.

28 Rudski LG, Gargani L, Armstrong WF, et al. Stressing the cardiopulmonary vascular system: the role of echocardiography. $J$ Am Soc Echocardiogr 2018;31:e11:527-50.

29 Naeije R, Saggar R, Badesch D, et al. Exercise-induced pulmonary hypertension: translating pathophysiological concepts into clinical practice. Chest 2018:154:10-15.

30 Lewis GD, Bossone E, Naeije R, et al. Pulmonary vascular hemodynamic response to exercise in cardiopulmonary diseases. Circulation 2013;128:1470-9. 